\title{
Análisis de las necesidades del alumnado de nuevo ingreso en los Grados en Magisterio: Implicaciones para el diseño del Plan de Orientación Universitaria en la Facultad de Educación de la Universidad de Zaragoza ${ }^{1}$
}

\author{
Elena Escolano-Pérez ${ }^{2}$, Manuel Lizalde Gil ${ }^{3}$, Rosa María Serrano Pastor ${ }^{4}$, Óscar \\ Casanova López ${ }^{5}$
}

Recibido: Octubre 2017 / Evaluado: Diciembre 2017 / Aceptado: Enero 2018

Resumen. El objetivo de este trabajo fue detectar las necesidades de información que presentaba el alumnado que comenzaba los Grados en Magisterio en Educación Infantil y en Educación Primaria en la Facultad de Educación en la Universidad de Zaragoza durante el curso académico 2015-16. Para ello, profesorado que impartía docencia en los mencionados Grados y que eran tutores del Plan de Orientación Universitaria (POU) de dicho centro, junto con la ayuda de mentores que participaban asimismo en el POU, elaboraron un cuestionario ad hoc. En él se preguntaba acerca de las necesidades de información que los estudiantes habían tenido en dos momentos temporales del curso académico: al iniciar sus estudios y tras finalizar el primer semestre. Los resultados obtenidos indican que en ambos momentos las mayores necesidades manifestadas por los estudiantes son de tipo académico. Las necesidades geográficas y administrativas son las segundas más demandadas al comenzar el Grado, y las de tipo personal y social, las terceras. En cambio, tras finalizar el primer semestre, estos dos tipos de necesidades alternan su grado de relevancia en el alumnado, de manera que las personales y sociales ocupan el segundo lugar y las geográficas y administrativas, el tercero. No obstante, los tres tipos de necesidades son más demandadas al comenzar el Grado, descendiendo su necesidad posteriormente. A partir de estos resultados se está en disposición de concretar el contenido del POU de la Facultad de Educación, pues se dispone de la información necesaria para el diseño y elaboración de actividades y materiales específicos que permitan responder a estas necesidades del alumnado. Ello contribuirá a facilitar su adaptación al entorno universitario y su rendimiento académico.

Palabras clave: Orientación universitaria; alumnado universitario de nuevo ingreso; necesidades percibidas; Espacio Europeo de Educación Superior.

1 Este trabajo forma parte del Proyecto de Innovación Docente (Ref. PIPOUZ_15_056), concedido por el Vicerrectorado de Política Académica de la Universidad de Zaragoza dentro del Programa de Incentivación del Plan de Orientación Universitaria en la Universidad de Zaragoza (PIPOUZ).

2 Universidad de Zaragoza (España).

E-mail: eescola@unizar.es

3 Universidad de Zaragoza (España).

E-mail: mboston@unizar.es

4 Universidad de Zaragoza (España).

E-mail: rmserran@unizar.es

5 Universidad de Zaragoza (España).

E-mail: ocasanov@unizar.es 


\title{
[en] Analysis of the needs of beginner students in the Teaching Degrees: Implications for the design of the University Orientation Plan in the Faculty of Education
}

\begin{abstract}
The aim of this work was to find out what are the needs of the students who started either the Degree in Early Childhood Education and the Degree in Primary Education in the Faculty of Education at the University of Zaragoza during the academic year 2015-16. In order to do so, teachers from both of the degrees mentioned above who were also form tutors of the University Counseling Center (Plan de Orientación Universitaria -POU- in Spanish) of the Faculty of Education, developed and distributed the ad hoc questionnaire. Some mentors, who also participated in the POU, helped in the elaboration of this questionnaire. It focuses on finding and evaluating the information needs that students encounter in two specific moments of their academic course, that is, once they start the degree and at the end of the first semester. Results indicate that in both moments, the greatest needs of the students are the academic ones. Thus, when students start the degree, geographic and administrative needs are the second most demanded, leaving the personal and social needs on the third place. However, by the end of the first semester, these two types of needs alternate their degree of relevance in the life of the students in order that personal and social needs occupy the second place, followed by geographical and administrative needs on the third place. Nevertheless, the three types of needs proved to be at a higher point at the beginning of the degree, but consequently decreasing after the first semester. These results allow to specify the content of the POU of the Faculty of Education. It not only allows to design and elaborate specific activities and materials in order to address these evolving needs that students face during their freshman year of University, but also to facilitate their adaptation to the university environment and therefore, to their academic performance.
\end{abstract}

Keywords: University Orientation; beginner university students; perceived needs; European Higher Education Area.

Sumario. 1. Introducción. 2. Método. 3. Resultados. 4. Conclusiones. 5. Referencias bibliográficas.

Cómo citar: Escolano-Pérez, E.; Lizalde Gil, M.; Serrano Pastor, R. M. y Casanova López, Ó. (2019). Análisis de las necesidades del alumnado de nuevo ingreso en los Grados en Magisterio: Implicaciones para el diseño del Plan de Orientación Universitaria en la Facultad de Educación de la Universidad de Zaragoza. Revista Complutense de Educación, 30 (2), 545-567.

\section{Introducción}

La entrada en la universidad es uno de los acontecimientos más importantes en la vida académica de una persona. Supone un momento clave que conlleva cambios que ponen a prueba su capacidad para adaptarse a un contexto desconocido y responder a numerosas demandas y dificultades para las que no siempre se encuentra preparada. Ello hace que, para muchos estudiantes, la entrada en la universidad resulte una experiencia compleja y estresante que puede provocar sentimientos de inseguridad, menor autoestima, sobrecarga de trabajo y elevada ansiedad (Álvarez-Pérez y López-Aguilar, 2017; García, Carpintero, Biencinto y Núñez, 2014).

A los cambios en el ambiente educativo y estrictamente académicos se unen otros factores que hacen compleja la transición a la universidad, como por ejemplo, la desinformación sobre el nuevo nivel educativo, la desmotivación del alumnado que no logra entrar en la carrera deseada y los estereotipos sobre la vida universitaria (Álvarez, Figuera y Torrado, 2011). La situación puede agravarse en aquellos casos en los que los estudiantes deben abandonar el domicilio familiar para cursar estudios universitarios, pues a las nuevas características y exigencias académicas se une tam- 
bién la necesidad de adaptación a un nuevo contexto social (Stroebe, Schut y Nauta, 2015). La combinación de estos factores conforma un riesgo para la permanencia e integración de los estudiantes. Todo ello ayuda a entender por qué la mayor tasa de abandono universitario se produce en el primer curso universitario (Bernardo et al., 2017; Esteban, Bernardo y Rodríguez-Muñiz, 2016).

La tasa de abandono constituye un indicador de la calidad de las instituciones universitarias, conllevando además numerosos costos personales, económicos y sociales (Colás, 2015). De ahí que las universidades españolas iniciaran actuaciones específicas dirigidas al descenso del abandono siguiendo las directrices del MECD y de entidades educativas europeas que establecen dos fases para ello: una primera destinada a la identificación de los factores principales de abandono universitario, seguida de otra referida al diseño e implementación de políticas de prevención, intervención y compensación. En relación con la primera fase, la literatura revela que son numerosos los factores que llevan al abandono universitario y que actúan en interacción, lo que hace que se esté ante un proceso altamente complejo, más aún considerando que estos factores y sus interacciones varían en función de características contextuales concretas de cada estudiante (Álvarez et al., 2011; Esteban et al., 2016). A pesar de estas diferencias, numerosos autores (Bernardo et al., 2015; Esteban et al., 2016) destacan que, al margen de cuestiones meramente académicas del alumnado, el abandono universitario con frecuencia se debe a un deficitario proceso de adaptación e integración a la vida universitaria, tanto en la dimensión académica como social. Ante este fenómeno, la orientación y la tutoría universitaria constituyen estrategias que pueden reducir este elevado abandono y mejorar los resultados académicos de los alumnos, ya que potencian una adecuada transición y ajuste al mundo universitario (Allueva, 2013; Bernardo et al., 2015; Bernardo et al., 2017).

Así lo recogen también numerosos documentos oficiales tanto nacionales (por ejemplo, Estatuto del Estudiante Universitario -BOE, 2010-) como internacionales (Report to the European Commission on Improving the quality of teaching and learning in Europe's higher education institutions -High Level Group on the Modernisation of Higher Education, 2013-) que destacan la necesidad de crear por parte de las instituciones universitarias estructuras de apoyo y orientación como elementos clave para facilitar la adaptación al entorno universitario y el rendimiento académico de los estudiantes. La inclusión en el contexto universitario a través de la orientación y tutoría se convierte en un aspecto clave en las metas de las políticas públicas a nivel nacional e internacional. La relevancia y beneficios de un buen proceso de orientación es tal para la formación académica y personal del alumnado que en nuestro país el Estatuto del Estudiante Universitario establece la orientación como un derecho del estudiante (Allueva, 2013; Allueva, Zulaica y Abadía, 2016).

Para lograr esta adaptación al entorno universitario a través de la orientación es necesario acabar con el enfoque reactivo de la misma hasta ahora frecuentemente presente y caracterizado por ofrecer actuaciones esporádicas y puntuales de carácter informativo, realizadas una vez han surgido las necesidades y dirigidas casi exclusivamente a aquellos estudiantes que las demandan. Contrariamente a ello, la orientación debe considerarse como un proceso: a) planificado a partir de una evaluación sistemática y científica de las necesidades expresadas por los estudiantes para fomentar determinadas competencias o para evitar que aparezcan dificultades o problemas; b) destinado a todo el alumnado; c) efectuado desde una perspectiva globalizadora e integradora de las distintas dimensiones del alumnado y por tanto, 
considerando todas sus necesidades: académicas, profesionales, personales, sociales, administrativas y geográficas (García, Asensio, Carballo, García y Guardia, 2005; Villena, Muñoz y Polo, 2013); d) atendiendo la perspectiva evolutiva del alumnado, lo que supone considerar que las necesidades y los problemas a los que se enfrentan los alumnos durante su formación universitaria no son siempre los mismos sino que cambian en función del momento en el que se encuentren (Pérez y Martínez, 2015).

Sin embargo, a pesar de que son muchos los documentos oficiales y los autores que defienden que la orientación debe ser planificada a partir del análisis de las necesidades de los estudiantes, existen resultados en la literatura que indican que estos, mayormente, opinan que la orientación no se planifica teniendo en cuenta sus necesidades (Guerra-Martín, Lima y Lima, 2016). De cara a superar estas limitaciones y crear estructuras de apoyo y orientación exitosas para la formación integral del alumnado, una de las perspectivas más aconsejadas y utilizadas en la literatura es conocer de primera mano las necesidades manifestadas por los propios implicados: los estudiantes (Álvarez-Pérez, 2012; Figuera y Coiduras, 2013; Martínez, Martínez y Pérez, 2016; Rodríguez-Hoyos, Calvo y Haya, 2015). Es en relación con este aspecto, conocer de primera mano las necesidades manifestadas por el propio alumnado para a partir de ahí desarrollar planes de orientación que respondan a las mismas, que se ha desarrollado este trabajo en la Facultad de Educación de la Universidad de Zaragoza.

Así, este trabajo se ubica dentro del Plan de Orientación Universitaria de la Universidad de Zaragoza -POUZ-, que comenzó a implantarse en el curso 2015-2016. El POUZ tiene como objetivo general "favorecer la integración, educación y desarrollo de los estudiantes en la Universidad, así como la inserción en el mundo laboral" (Allueva et al., 2016, p. 2275). Dada la diversidad de Grados que existen en la Universidad de Zaragoza y las características particulares de estos, sus estudiantes presentarán necesidades diferentes. Es por esto que, a partir de las líneas generales del POUZ, cada centro debe elaborar su propio Plan de Orientación Universitaria (POU) personalizado (Allueva et al., 2016). Para ello, y de acuerdo con distintos autores (Altschuld y Watkins, 2014; Álvarez-Pérez y López-Aguilar, 2017; Chacón, Sanduvete, Portell y Anguera, 2013) que afirman que la primera fase de todo programa de intervención (como es el POU) es el análisis inicial de las necesidades, se planteó este trabajo cuyo objetivo fue conocer de primera mano las necesidades del alumnado de nuevo ingreso en la Facultad de Educación (concretamente, alumnado de nuevo ingreso en los Grados en Magisterio en Educación Infantil y Magisterio en Educación Primaria) en el curso 2015-2016. Ello supondrá el punto de partida para poder diseñar posteriormente las acciones de orientación del POU de la Facultad de Educación que, contextualizadas en el propio centro, respondan a las demandas, intereses y necesidades manifestadas por el alumnado y, por lo tanto, que contribuyan a su proceso de adaptación e integración en la Facultad.

\section{Método}

\subsection{Participantes}

La muestra inicial estaba formada por 218 estudiantes de nuevo ingreso en los Grados en Magisterio en Educación Infantil y Magisterio en Educación Primaria ${ }^{6}$ en la

Los títulos que habilitan para el ejercicio de la profesión regulada de Maestro en Educación Infantil y Maestro en Educación Primaria se denominan en la Universidad de Zaragoza, respectivamente, Magisterio en Educación Infantil y Magisterio en Educación Primaria, tal y como queda recogido en el BOE n 77 de 29 de marzo de 2014. 
Facultad de Educación de la Universidad de Zaragoza en el curso 2015-16. Representaban el $60.55 \%$ de todos los estudiantes matriculados por primera vez en dichos Grados en ese curso escolar. La distribución de los participantes atendiendo al Grado que estudiaban y el porcentaje de alumnado que representaban respecto al total de matriculados en primer curso aparecen recogidos en la Tabla 1.

Tabla 1: Estudiantes de nuevo ingreso en los Grados en Magisterio en Educación Infantil y Magisterio en Educación en Primaria: matriculados y participantes en el estudio.

\begin{tabular}{|l|c|c|c|}
\hline \multicolumn{1}{|c|}{ Estudiantes } \\
\hline & Matriculados & Participantes & $\begin{array}{c}\text { \% Participantes } \\
\text { respecto al total } \\
\text { Matriculados }\end{array}$ \\
\hline Magisterio en Educación Infantil & 120 & 98 & 81.67 \\
\hline Magisterio en Educación Primaria & 240 & 120 & 50.00 \\
\hline Total & 360 & 218 & 60.55 \\
\hline
\end{tabular}

Centrándonos en los 218 participantes que componían la muestra total de este estudio (Tabla 2), el 44.95\% de ellos pertenecía al Grado en Magisterio en Educación Infantil y el 55.05\% restante al Grado en Magisterio en Educación Primaria. Su edad media era de 19.82 años $(\mathrm{DT}=3.98)$, oscilando en un rango comprendido entre los 18 y los 49 años. La mayor parte de ellos (55.05\%) tenía una edad de 18 años y un $20.64 \%$ tenía 19 años, por lo que tres cuartas partes de la muestra $(75.69 \%)$ estaba formada por estudiantes de 18 y 19 años. Un $16.51 \%$ tenía entre 20 y 24 años; $4.13 \%$ entre 25 y 30 años y solo un $3.67 \%$ de la muestra eran mayores de 30 años.

En cuanto al sexo, el $80.28 \%$ de los participantes eran mujeres -tendencia normal en estas titulaciones, de acuerdo con Martínez et al. (2016)- y el $19.72 \%$ restante eran hombres.

La mayoría de los estudiantes participantes $(82.57 \%)$ accedieron a la Universidad a través de Bachillerato. Un 12.84\% accedió a través de Ciclos Formativos de Grado Superior; un $3.67 \%$ a través de la prueba de acceso para mayores de 25 y de 40 años, y solo un $0.92 \%$ a través de otras modalidades de acceso (COU; Titulada y mayores de 45 años).

Fundamentalmente se trataba de estudiantes que, durante el curso, residían con su familia habitual $(76.15 \%)$. El $10.09 \%$ compartía piso con otros estudiantes y el $8.72 \%$ residía en colegios mayores o residencias. Un $5.05 \%$ de los participantes vivía solo o con otros familiares como abuelos y tíos.

Tabla 2: Características de la muestra.

\begin{tabular}{|l|l|l|}
\hline \multicolumn{1}{|c|}{ Variables } & N & \% \\
\hline Grado que cursan & & \\
\hline Educación Infantil & 98 & 44.95 \\
\hline
\end{tabular}




\begin{tabular}{|l|c|c|}
\hline \multicolumn{1}{|c|}{ Variables } & N & \% \\
\hline Educación Primaria & 120 & 55.05 \\
\hline Sexo & & \\
\hline Masculino & 43 & 19.72 \\
\hline Femenino & 175 & 80.28 \\
\hline Edad (años) & & \\
\hline 18 & 120 & 55.05 \\
\hline 19 & 45 & 20.64 \\
\hline 20 & 11 & 5.05 \\
\hline 21 & 9 & 4.13 \\
\hline 22 & 7 & 3.21 \\
\hline 23 & 5 & 2.29 \\
\hline 24 & 4 & 1.83 \\
\hline $25-30$ & 9 & 4.13 \\
\hline$>30$ & 180 & 3.67 \\
\hline Acceso a la universidad Bachillerato & 28 & 12.84 \\
\hline Ciclos Formativos Grado Superior & 19 & 3.67 \\
\hline Acceso $>25$ o $>40$ & 166 & 76.15 \\
\hline Otras & 22 & 10.09 \\
\hline Residencia durante el curso & & 8.72 \\
\hline Su familia & 19.05 \\
\hline Piso compartido con estudiantes & & \\
\hline Colegio mayor o residencia & & \\
\hline Otros & & \\
\hline
\end{tabular}

\subsection{Procedimiento}

Este trabajo constituye un estudio descriptivo tipo encuesta en el que se hace uso del cuestionario como instrumento para la recogida de información (Bisquerra, 2004). Consecuentemente, para dar respuesta a nuestro objetivo se siguieron las etapas propias de la investigación por encuesta (Cohen y Manion, 2002), ajustándolas a las necesidades que marcaba nuestro propio trabajo. De este modo, se distinguen tres principales fases en nuestra investigación: 1) construcción del cuestionario que permita recoger las necesidades de información del alumnado; 2) recogida de datos; 3) análisis de datos e interpretación de los resultados. 


\section{1) Construcción del cuestionario}

La construcción del cuestionario implicó diferentes estrategias metodológicas:

\subsection{Delimitación de las dimensiones e indicadores a incluir en el cuestionario}

Para delimitar las dimensiones e indicadores sobre los que se pretendía obtener información se atendió a: a) los principios del POUZ que establecen que la adaptación e integración de los estudiantes que acceden a la Universidad debe realizarse desde tres áreas principales: académica; personal y social; geográfica y administrativa (Allueva et al., 2016); b) la literatura científica sobre el tema, revisando tanto trabajos teóricos como empíricos sobre orientación, y más exactamente sobre orientación en el contexto universitario y las necesidades de su alumnado de nuevo ingreso, prestando especial atención a aquellos trabajos que abordaban cuestiones referidas a alguna de estas tres áreas principales desde las que debe realizarse el POUZ. Asimismo se analizaron instrumentos ya elaborados para fines similares al de nuestra investigación (Álvarez-Pérez, 2012; García, 2010; Rodríguez-Hoyos et al., 2015).

Mediante trabajo cooperativo y grupo de discusión en el que participaron cinco profesores con formación y experiencia en orientación y docencia y que eran tutores del POU, se determinaron tres dimensiones a incluir en el cuestionario, cada una de ellas con diferentes indicadores:

a) Datos de identificación: se recoge información sobre algunas de las variables de identificación del alumnado: Grado que cursaban (Magisterio en Educación Infantil o Magisterio en Educación Primaria); edad; sexo; modalidad de acceso a la universidad y lugar de residencia habitual durante el curso.

b) Grado de necesidad de ser informado sobre diferentes asuntos: se trata de la dimensión y subdimensiones más relevantes del cuestionario, dado que se pregunta al alumnado la necesidad que tiene respecto a ser informado sobre distintas cuestiones académicas, personales y sociales, así como geográficas y administrativas. En concreto, se solicita al alumnado que indique cuál fue el grado de necesidad de ser informado que experimentó al respecto en dos momentos diferentes del curso: al comenzar el Grado y tras finalizar el primer semestre. El hecho de preguntar por las necesidades que tuvieron los estudiantes en estos dos momentos temporales responde a razones teóricas y empíricas. De acuerdo con la literatura científica (Allueva et al., 2016; Figuera y Álvarez, 2014), existen varios momentos de actuación claves para la integración de los estudiantes en la Universidad, siendo estos (al comenzar sus estudios y tras el primer semestre) dos de ellos. Además, la orientación en ambos momentos es competencia de los tutores del POU (esto no es así en otros momentos clave como por ejemplo, previamente al ingreso en la universidad), pudiendo por tanto los tutores diseñar recursos y actividades para su implantación en los meses restantes del curso en función de las necesidades del alumnado.

c) Comentarios o sugerencias sobre el POU: el cuestionario finaliza solicitando al alumnado comentarios o sugerencias de mejora que desee realizar sobre el POU.

1.2. Elaboración y selección del tipo de preguntas e ítems del cuestionario a partir de las dimensiones e indicadores establecidos

A través de trabajo cooperativo se elaboró un banco de ítems referidos a las tres dimensiones determinadas previamente: datos de identificación; necesidad de ser informado; y comentarios/sugerencias sobre el POU. La mayor parte de ellos fueron 
referidos principalmente a la segunda dimensión, es decir, a las necesidades de ser informado que el alumnado de nuevo ingreso podría presentar en cada una de las tres áreas que componen el POUZ, dado que era el objetivo principal de este trabajo.

Se decidió combinar en el cuestionario diversas tipologías de preguntas: i) preguntas cerradas de elección única y preguntas semicerradas también de elección única para recoger los datos de identificación del alumnado; ii) ítems tipo Likert con 4 alternativas de respuesta de elección única en las que se establece una graduación ( $1=$ ninguna necesidad; $2=$ poca necesidad; $3=$ bastante necesidad; $4=$ mucha necesidad) para conocer el grado de necesidad que presentaba el alumnado de ser informado sobre distintos aspectos; iii) una pregunta abierta para recoger comentarios o sugerencias sobre el POU. De este modo, se originó un instrumento mixto.

Este banco de ítems fue expuesto a un proceso de revisión continua tanto por parte de cada uno de los cinco docentes/tutores participantes en la construcción del cuestionario como conjuntamente por todos ellos. De este modo se llegó a elaborar una primera versión del cuestionario.

\subsection{Análisis de la validez del cuestionario: revisión de expertos}

Para analizar la validez de contenido del cuestionario elaborado se recurrió al juicio de expertos. El objetivo principal fue constatar si los elementos que componían el cuestionario eran suficientes y adecuados para responder al objetivo de investigación, o si por el contrario, quedaban excluidos elementos importantes; además de comprobar si existían elementos redundantes. Se contó con la valoración de cuatro profesores expertos en orientación y tutoría universitaria, metodología de investigación y en el POU. Las sugerencias aportadas por los distintos expertos fueron introducidas en el cuestionario, originándose una nueva versión.

Dicha versión del cuestionario fue entregada a alumnado de la Facultad de los cursos $3^{\circ}$ y $4^{\circ}$ que participaban como mentores en el POU (lo cual implicaba asimismo que eran buenos conocedores de la Facultad, la Universidad y de cuestiones generales sobre orientación, pues recibieron formación sobre ello para poder formar parte del grupo de mentores del POU). Su labor fue comprobar el grado de comprensión de las instrucciones dadas en el cuestionario y la adecuación del vocabulario para que los ítems fueran entendidos de modo unívoco por el alumnado. Para ello se llevó a cabo un grupo de discusión. Las propuestas resultantes se introdujeron en otra versión del cuestionario que resultó ser la definitiva.

\subsection{Redacción final del cuestionario.}

La versión final del cuestionario (Anexo 1) está compuesta, además de por los datos de identificación, por un total de 25 ítems referidos a posibles necesidades de información que puede presentar el alumnado de nuevo ingreso en relación con cuestiones pertenecientes a tres ámbitos o áreas: académica (8 ítems); personal y social ( 7 ítems); geográfica y administrativa (10 ítems). El cuestionario demanda que cada estudiante señale cuál es el grado de necesidad que tiene de ser informado sobre cada uno de los aspectos indicados en los ítems en dos momentos diferentes del curso: al comenzar el Grado y tras finalizar el primer semestre. La escala de respuesta a cada ítem es de tipo Likert de 4 puntos siendo: $1=$ ninguna necesidad; $2=$ poca necesidad; $3=$ bastante necesidad; 4= mucha necesidad. El cuestionario también consta de una pregunta abierta para que el alumnado realice cualquier comentario o sugerencia de mejora respecto al POU. 


\section{5.- Análisis de la fiabilidad.}

Los análisis realizados para comprobar la consistencia interna total del cuestionario construido arrojaron un alfa de Cronbach de .934, lo que de acuerdo con George y Mallery (2003) indica una excelente fiabilidad del instrumento. La consistencia interna para cada una de las tres subescalas de necesidades fue en todos los casos excelente (alfa de Cronbach necesidades administrativas y geográficas $=.90$ ) o buena (alfa de Cronbach necesidades académicas $=.84$; alfa de Cronbach necesidades personales $=.87)$.

\section{2) Recogida de datos}

La administración del cuestionario tuvo lugar durante el mes de febrero, una vez ya finalizado el primer semestre. Se llevó a cabo en el aula habitual de cada grupo de estudiantes y en horario de clase con la finalidad de conseguir un elevado número de respuestas por parte del alumnado de nuevo ingreso en la Facultad. A cada estudiante se le entregó en papel el cuestionario para su contestación anónima. Antes de proceder a su contestación, se explicó a los estudiantes la forma de responder y la importancia de contestar todas las preguntas con sinceridad. Se destacó la relevancia que ello tenía para poder diseñar un POU que se ajustara a sus necesidades. El tiempo necesario para cumplimentar el cuestionario fue, máximo, de 15 minutos. Finalmente, se agradeció la participación a todo el alumnado.

3) Análisis de datos e interpretación de los resultados.

Dado el objetivo de este estudio, solo nos centramos en el análisis del grado de necesidad que tiene el alumnado de nuevo ingreso de ser informado en cada uno de los aspectos recogidos en el área académica, personal y social, administrativa y geográfica al empezar el Grado y al finalizar el primer semestre del mismo. Así, en este trabajo no analizamos las respuestas a la pregunta abierta sobre comentarios y sugerencias de mejora del POU.

Una vez vaciadas las respuestas de los estudiantes en una hoja Excel, se procedió a su análisis cuantitativo haciendo uso del programa de análisis estadístico SPSS 19.0 para Windows. Se realizaron análisis univariables (frecuencias, porcentajes y estadísticos descriptivos de tendencia central (media) y de variabilidad (desviación típica)) cuya finalidad es descriptiva. En concreto, se calculó para cada uno de los dos momentos temporales sobre los que se preguntaba al alumnado por sus necesidades (al comenzar el Grado y tras el primer semestre) los siguientes aspectos: a) frecuencia y porcentaje de estudiantes que manifestaron cada uno de los grados de necesidad ( $1=$ ninguna necesidad; $2=$ poca; $3=$ bastante; $4=$ mucha necesidad) en cada ítem; b) grado medio de necesidad de cada ítem y desviación típica; c) grado medio de necesidad y desviación típica de cada una de las tres tipologías de necesidades: académicas, personales y sociales, y geográficas y administrativas.

El análisis de los datos fue realizado conjuntamente para todo el alumnado participante, es decir, sin diferenciar su pertenencia al Grado en Magisterio en Educación Infantil o al Grado en Magisterio en Educación Primaria, ya que el POU de la Facultad de Educación es único sin especificar diferencias entre los Grados que se imparten en el centro. Recordemos que ello responde a los principios del POUZ, que establece líneas generales y comunes para su desarrollo para toda la Universidad de 
Zaragoza, con especificaciones a realizar para el alumnado de cada centro (no de cada titulación que se imparta en el mismo).

Los resultados de dichos análisis se presentan a continuación.

\section{Resultados}

Primeramente se presentan los resultados referidos a las necesidades de información que manifiestan tener los estudiantes al comenzar el Grado (Tabla 3). Posteriormente se expondrán aquellos relativos a sus necesidades al finalizar el primer semestre (Tabla 4), estableciendo una comparativa con los anteriores (Figuras 1, 2, 3 y 4).

Atendiendo al tipo de necesidades (académicas; personales y sociales; geográficas y administrativas) manifestadas por los estudiantes al iniciar el Grado (Tabla 3), en términos generales, todas ellas son percibidas "bastante" necesarias (respuesta 3 del cuestionario). Más específicamente, las de tipo académico son las más necesitadas $(M=3.15 ; \mathrm{DT}=0.78)$, seguidas de las geográficas y administrativas $(\mathrm{M}=2.83$; $\mathrm{DT}=0.94)$ y por último, las personales y sociales $(\mathrm{M}=2.77$; $\mathrm{DT}=0.87)$.

Las valoraciones que los estudiantes manifiestan respecto a estas necesidades son bastantes homogéneas entre todos ellos, tal y como reflejan los valores de las correspondientes desviaciones típicas, si bien destaca que es precisamente en las necesidades más demandadas (las académicas) donde los estudiantes muestran mayor grado de acuerdo sobre la necesidad de recibir información (menor desviación típica $\mathrm{DT}=0.78)$.

Atendiendo a las necesidades concretas que conforman cada uno de los tres grandes tipos o categorías de necesidades, se obtienen los siguientes resultados.

En la categoría de necesidades académicas, y atendiendo a la media obtenida en cada ítem, todas las cuestiones son percibidas por los estudiantes como "bastante" necesarias al empezar sus estudios. A pesar de existir poca diferencia en cuanto al grado de necesidad entre ellas, la más necesaria es el conocimiento sobre plataformas virtuales $(\mathrm{M}=3.34$; $\mathrm{DT}=0.81)$. La mitad del alumnado $(51.38 \%)$ indica tener "mucha" necesidad de ser informado sobre ello y un 33.49\%, "bastante" necesidad. Esta cuestión relativa a información sobre el uso de plataformas virtuales es la única necesidad donde la mayor parte del alumnado, más de la mitad (51.38\%), manifiesta tener "mucha" necesidad de información. En las otras cuestiones siempre predomina el porcentaje de alumnos que indica tener "bastante" necesidad, salvo en el conocimiento de procedimientos administrativos donde existe el mismo porcentaje de alumnos que lo consideran "bastante" y "muy necesario" (35.78\%). Sin embargo, es precisamente en referencia a esta necesidad donde existe el mayor porcentaje de estudiantes (6.42\%) que responden no tener "ninguna" necesidad. Este mayor porcentaje de estudiantes que indican no tener "ninguna" necesidad, junto con un porcentaje relativamente importante de estudiantes $(22.02 \%)$ que indican tener "poca" necesidad de ser informados sobre ello, además de su menor media $(\mathrm{M}=3.01$; $\mathrm{DT}=$ 0.92), convierten el conocimiento de los procedimientos administrativos en la cuestión académica "menos" necesaria para el alumnado.

En cuanto a las necesidades geográficas y administrativas de los estudiantes, su mayor necesidad es disponer de más información sobre becas $(\mathrm{M}=3.21$; $\mathrm{DT}=0.92)$. Un $48.17 \%$ del alumnado lo considera "muy" necesario y un $30.28 \%$, "bastante" necesario. Por el contrario, en este ámbito geográfico y administrativo, lo que los 
estudiantes perciben como menos necesario es la información sobre recursos y servicios complementarios $(\mathrm{M}=2.38$; $\mathrm{DT}=1.09)$. Un $26.15 \%$ del alumnado manifiesta no tener "ninguna" necesidad de ser informado sobre ello y un $30.73 \%$ tener "poca" necesidad. Estos resultados pueden deberse fundamentalmente a que en la redacción del ítem se indicó como ejemplo de estos servicios los referidos a alojamiento, y la mayor parte de la muestra $(76.15 \%)$ residía con su familia habitual. Además hay que considerar que los estudiantes que necesitan de alojamiento, por lo general, ya disponen de él antes de comenzar el curso, por lo que la información sobre posibilidades de alojamiento, en caso de que haya sido necesaria, ya ha tenido que recibir respuesta. No obstante, existe todavía un $21.10 \%$ de estudiantes que indica tener "mucha" necesidad de ser informados al respecto. Sin embargo, es cierto que este porcentaje de alumnado es comparativamente menor al de alumnos que indican tener "mucha" necesidad sobre las otras cuestiones geográficas y administrativas.

Por último, en cuanto a las necesidades personales y sociales (recordemos que en conjunto resultan las menos necesarias), el alumnado manifiesta que su mayor necesidad en esta área es ser informado sobre cursos complementarios (voluntariado, etc.) $(\mathrm{M}=3.04$; $\mathrm{DT}=0.91)$. Un $36.70 \%$ de estudiantes indican tener "mucha" necesidad sobre ello y un $35.78 \%$, "bastante". Por el contrario, la necesidad personal y social sobre la que los estudiantes perciben necesitar menos información es la referida a relaciones y resolución de conflictos con compañeros, que es considerada en un punto medio entre "poco y bastante" necesaria $(M=2.45$; $\mathrm{DT}=0.91)$. Un $15.14 \%$ del alumnado indica no tener "ninguna" necesidad de ello y un 38.07\%, "poca". Tan solo un $13.76 \%$ del alumnado manifiesta tener "mucha" necesidad sobre esta cuestión.

Respecto a las necesidades al finalizar el primer semestre (Tabla 4), se observa que, en términos generales, todas ellas son menos intensas que al iniciar el Grado. Es decir, conforme avanza el curso, los estudiantes perciben tener una menor necesidad de ser informados sobre las distintas cuestiones recogidas en el cuestionario.

Tal y como refleja la Figura 1, las cuestiones académicas son las que demuestran un descenso mayor (0.61 puntos) en cuanto a la percepción de necesidad por parte de los estudiantes $(\mathrm{M}$ al iniciar el semestre $=3.15$ frente a $\mathrm{M}$ al finalizar el semestre $=$ 2.54), pero a pesar de ello, continúan siendo las más demandadas. Las cuestiones geográficas y administrativas descienden 0.49 puntos en su media de necesidad, de modo que pasan de ser las segundas más necesarias a las terceras más necesarias ( $\mathrm{M}$ al iniciar semestre $=2.83$ vs M al finalizar semestre $=2.34$ ). Así, este descenso en importancia hace que al finalizar el semestre sean percibidas por los estudiantes como las menos necesarias sobre las que recibir información. Las cuestiones personales y sociales son las que menos cambian en cuanto a su percepción de necesidad (descienden solo 0.26 puntos; $\mathrm{M}$ al iniciar semestre $=2.77 \mathrm{vs} \mathrm{M}$ al finalizar semestre $=$ 2.51). Sin embargo, este menor descenso en su grado de necesidad, junto al descenso importante de las geográficas y administrativas, hace que las cuestiones personales y sociales hayan pasado de ser consideradas como las menos relevantes o menos necesarias al comenzar los estudios a ocupar el segundo lugar una vez finalizado el primer semestre. Así, aunque en término absolutos (es decir, según su media) su necesidad es menor al terminar el semestre que al iniciarlo, al ordenarlas en función de su grado de necesidad comparativamente al resto de cuestiones, las personales y sociales ascienden una posición en la jerarquía de necesidades (Figura 1). 
Tabla 3: Necesidades del alumnado al iniciar el Grado.

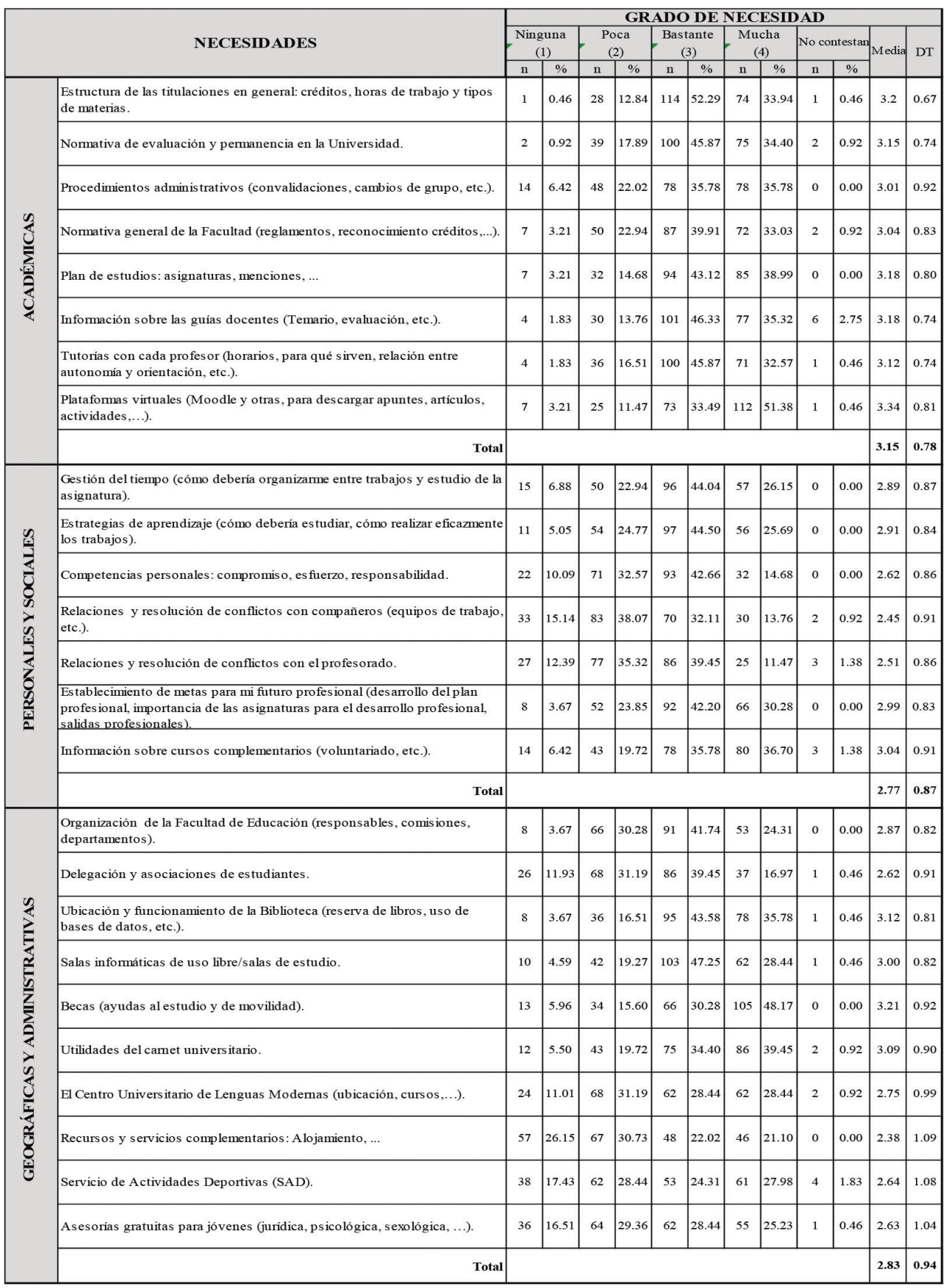


Tabla 4: Necesidades del alumnado al finalizar el primer semestre.

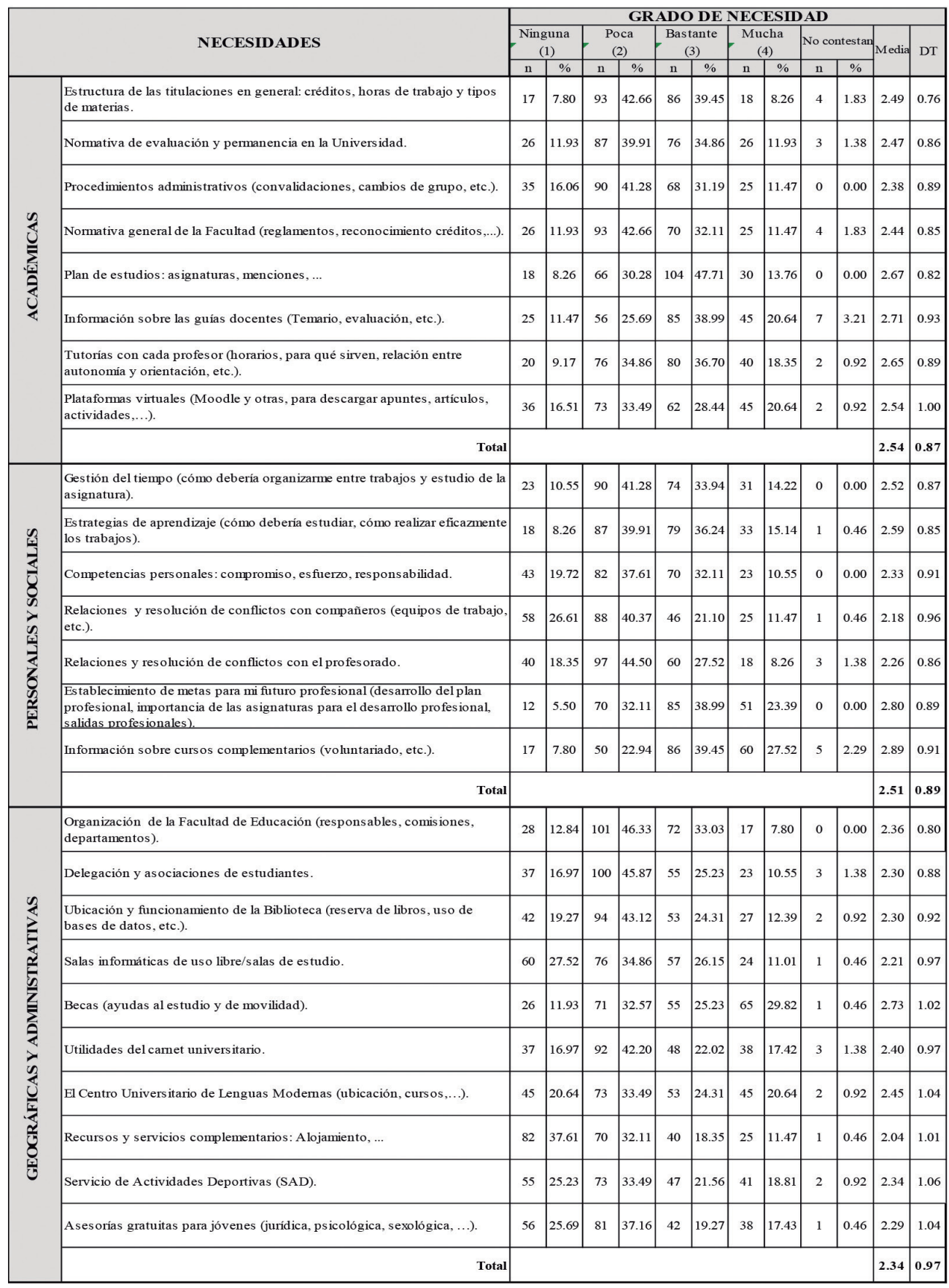




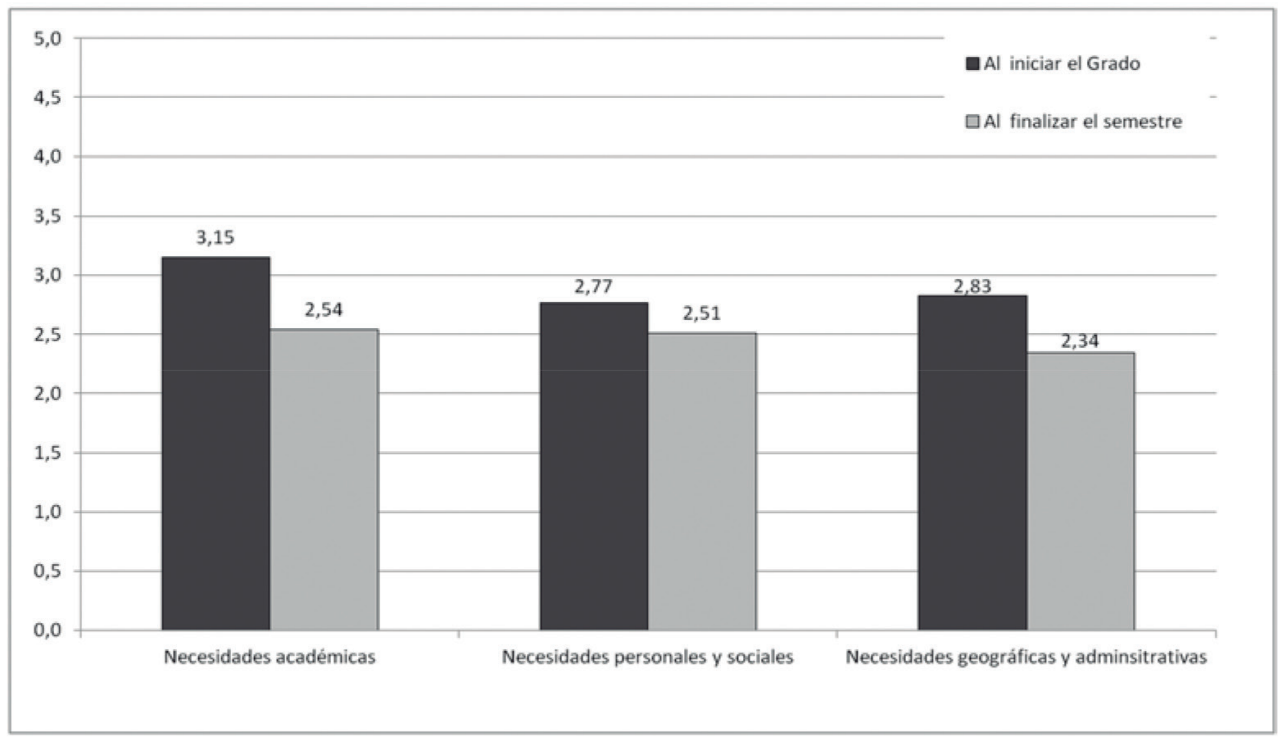

Figura 1. Grado de necesidad del alumnado de ser informado sobre cuestiones académicas, personales y sociales, y geográficas y administrativas al iniciar el Grado y al finalizar el primer semestre.

La menor necesidad de información de los estudiantes al finalizar el primer semestre, comparativamente con la manifestada en sus inicios, se produce no solo a nivel de categorías o tipologías de necesidades, sino también en todas y cada una de las necesidades específicas que las componen. Esta menor necesidad de información se aprecia en el descenso de la media de todas y cada una de las distintas necesidades pero también, y principalmente, al analizar los porcentajes de estudiantes que responden señalando un grado de necesidad u otro (ver Tabla 3 y Tabla 4). En este sentido, los resultados indican que, para todas y cada una de las necesidades, desciende el porcentaje de estudiantes que indica tener "mucha" necesidad de ser informado sobre cada cuestión y aumenta el porcentaje de estudiantes que manifiesta no tener "ninguna" necesidad de ser informado sobre ello.

Dentro de las necesidades académicas, ahora aparece como la más valorada la obtención de información sobre las guías docentes (Figura 2). Aunque atendiendo a su media esta cuestión es menos necesaria al finalizar el semestre $(\mathrm{M}=2.71)$ que al inicio del curso $(\mathrm{M}=3.18)$, comparativamente con el grado de necesidad de las restantes cuestiones académicas al finalizar el semestre asciende un puesto en la clasificación de necesidades académicas y se convierte en la mayor necesidad para los estudiantes: un $20.64 \%$ de alumnado manifiesta tener "mucha" necesidad y un $38.99 \%$ tener "bastante" necesidad. La necesidad académica menos valorada al acabar el semestre sigue siendo la misma que al iniciarlo -conocer procedimientos administrativos-, pero es percibida como menos necesaria todavía de lo que lo era al comenzar el curso ( $\mathrm{M}$ al finalizar primer semestre $=2.38 \mathrm{vs} \mathrm{M}$ al iniciar primer semestre $=3.01)$. Además, ahora es considerablemente mayor el porcentaje de alumnos que indica tener "poca" (41.28\%) o "ninguna" necesidad (16.06\%). 


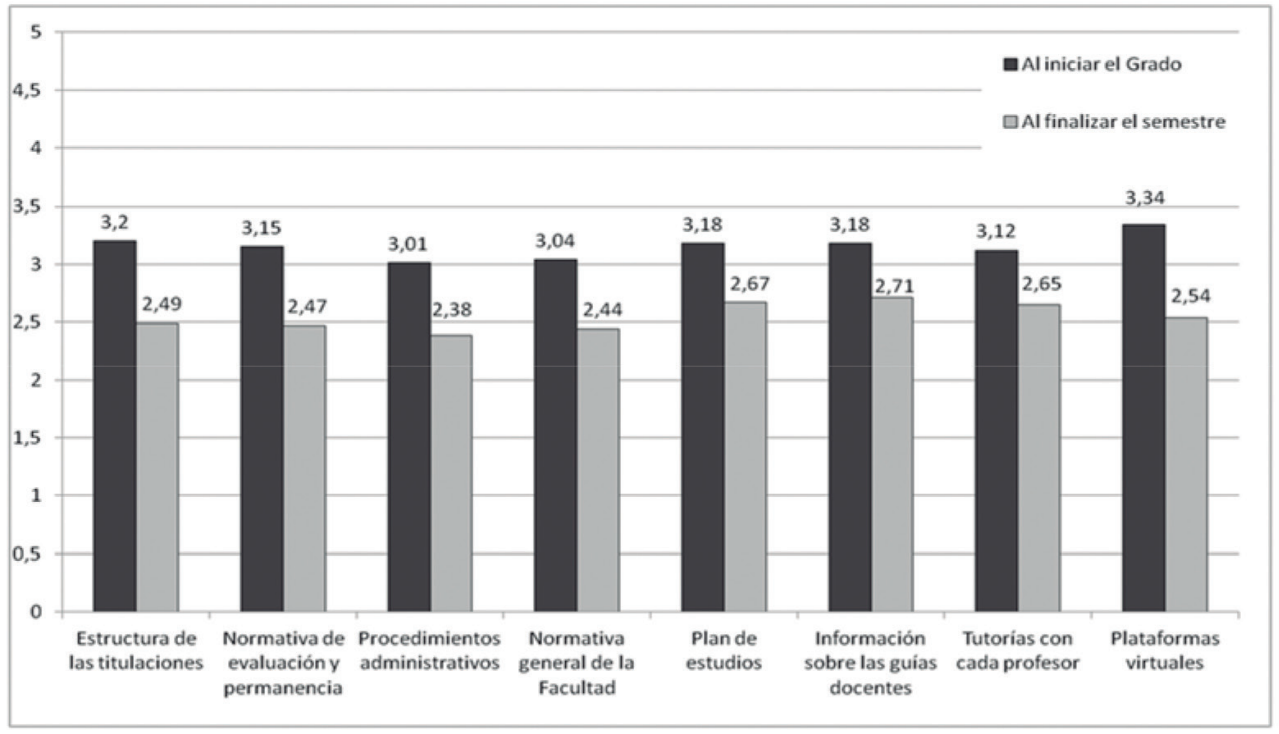

Figura 2. Grado de necesidad del alumnado de ser informado sobre cuestiones académicas al iniciar el Grado y al finalizar el primer semestre.

En cuanto a las cuestiones personales y sociales, según sus medias (Figura 3), la considerada más necesaria al acabar el semestre es la obtención de información sobre cursos complementarios $(\mathrm{M}=2.89)$. Por el contrario, la menos necesaria es la referente a relaciones y resolución de conflictos con compañeros $(\mathrm{M}=2.18)$. Llama la atención que en esta categoría de necesidades personales y sociales, aunque todas ellas descienden en cuanto a su grado medio de percepción de necesidad, la más y menos valorada son las mismas al iniciar los estudios que tras finalizar el primer semestre. Asimismo, en ambos momentos temporales, la obtención de información sobre cursos complementarios es la necesidad sobre la cual mayor porcentaje de estudiantes indica tener "mucha" necesidad de información (aunque tal y como se ha indicado, desciende su necesidad con el paso del tiempo: al finalizar el semestre $27.52 \%$ del alumnado indica tener "mucha" necesidad vs al $36.70 \%$ al iniciar el semestre). En el sentido opuesto, en cuanto a no tener "ninguna" necesidad de información, el mayor porcentaje de respuestas del alumnado en ambos momentos recae sobre relaciones y resolución de conflictos con compañeros $(26.61 \%$ al finalizar el semestre vs $15.14 \%$ al iniciarlo). Todo ello permite concluir diciendo que las necesidades personales y sociales del alumnado descienden al finalizar el semestre, si bien, a pesar del paso del tiempo, se mantienen aquellas cuestiones sobre las que el alumnado percibe más y menos necesidad de información.

Esta misma situación que acaba de mencionarse se repite en las necesidades de tipo geográfico y administrativo (Figura 4). Es decir, aunque nuevamente todas las cuestiones son percibidas como menos necesarias de información al finalizar el semestre, la información sobre becas continúa siendo la más necesaria $(\mathrm{M}=2.73)$ y la relativa a recursos y servicios complementarios, la menos necesaria $(M=2.04)$. Sus porcentajes de respuestas corroboran estos datos aportados por las medias, en cuanto 
que en ambos momentos (inicio y fin del semestre) la información sobre becas recibe el mayor porcentaje de respuestas referidas a "mucha" necesidad (aunque este porcentaje desciende al finalizar el semestre casi hasta la mitad: $48.17 \%$ vs $29.82 \%$ ) y la información sobre recursos y servicios complementarios recibe el mayor porcentaje de respuestas "ninguna" necesidad (ascendiendo del 26.15\% al 37.61\% al finalizar el semestre). En suma, al igual que sucede con las cuestiones personales y sociales, al finalizar el semestre el alumnado percibe menor necesidad de ser informado sobre aspectos geográficos y administrativos que cuando comenzó el curso, pero las cuestiones específicas sobre las que indica tener más y menos necesidad de información son las mismas.

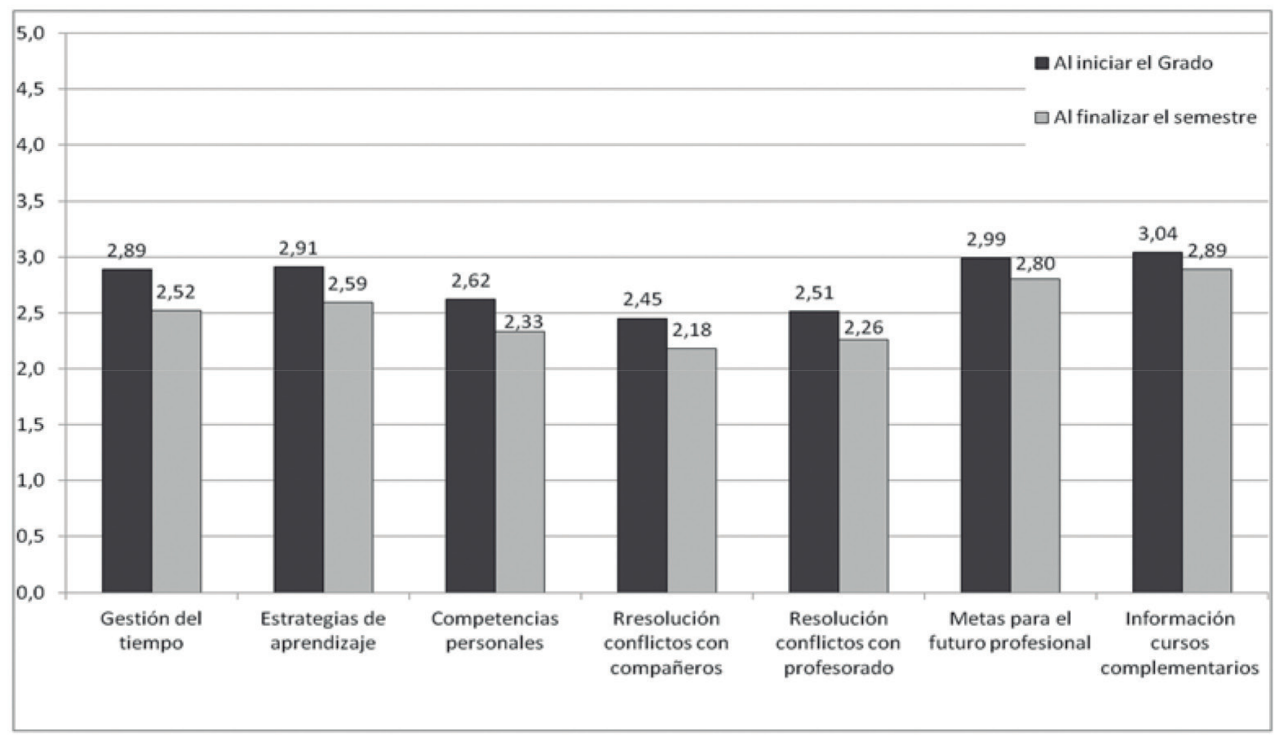

Figura 3. Grado de necesidad del alumnado de ser informado sobre cuestiones personales y sociales al iniciar el Grado y al finalizar el primer semestre.

\section{Conclusiones}

Los resultados obtenidos indican que la información sobre cuestiones académicas constituye la mayor necesidad de los estudiantes de nuevo ingreso en la Facultad de Educación, independientemente del momento del curso en el que estos se encuentren (al inicio del Grado o al finalizar el primer semestre). Estos resultados apuntan en la misma línea que los obtenidos por estudios similares realizados en otras universidades españolas (van-der Hofstadt, Quiles, Quiles y Rodríguez, 2005; Villena et al., 2013) en cuanto que cuestiones referidas a exámenes, asignaturas y planes de estudio aparecen repetidamente como algunos de los aspectos que más preocupan al alumnado. Sin embargo, es cierto que los resultados obtenidos en nuestro estudio indican que, tanto estas necesidades académicas como las restantes tipologías de necesidades evaluadas (personales y sociales, y geográficas y administrativas) van perdiendo peso en el alumnado conforme avanza el curso académico. Así, todas las necesidades 
de información son más demandadas al iniciar el Grado que posteriormente. Sin embargo, ello no significa que conforme el curso va avanzando desaparezcan las necesidades del alumnado. De hecho, así lo manifiestan nuestros resultados. Por tanto, la orientación no debe ser una acción puntual sino permanente, pero ajustada a las necesidades cambiantes (Pérez y Martínez, 2015).

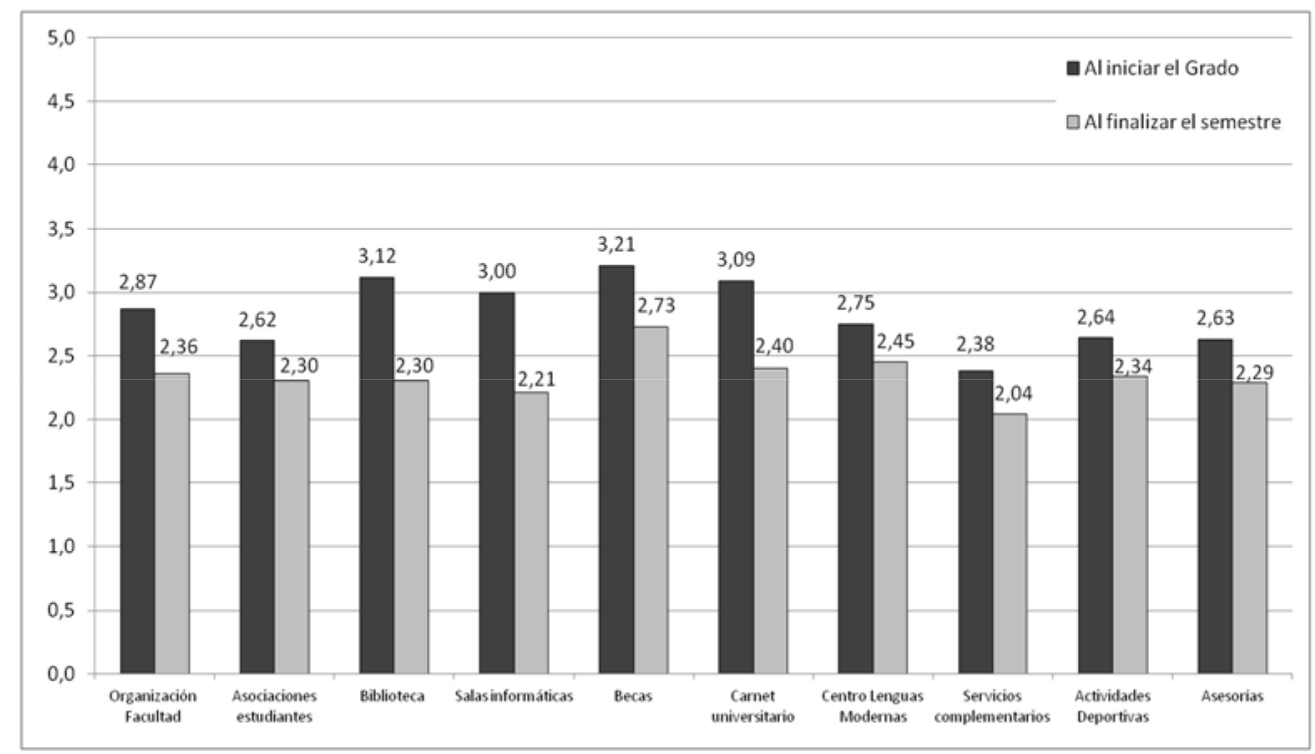

Figura 4. Grado de necesidad del alumnado de ser informado sobre cuestiones geográficas y administrativas al iniciar el Grado y al finalizar el primer semestre.

En relación con ello, los resultados obtenidos referentes al distinto grado de necesidad de información que tienen los estudiantes sobre diversas cuestiones en momentos diferentes del curso permiten planificar el cronograma a seguir en el POU. Ajustarnos en cada momento a las necesidades del alumnado y responder a las mismas en el momento oportuno será un aspecto clave para la percepción de utilidad del POU por parte del alumnado, y consecuentemente, para su participación y permanencia en él.

En función de todo lo expuesto anteriormente, podemos concluir que el cuestionario elaborado ad hoc ha resultado un instrumento útil para alcanzar nuestro objetivo, ya que ha permitido conocer las necesidades de información que tiene el alumnado que comienza los Grados en Magisterio en Educación Infantil y Magisterio en Educación Primaria en la Facultad de Educación de la Universidad de Zaragoza, permitiendo además distinguir entre su grado de necesidad al inicio de sus estudios y tras el primer semestre. Además, la aplicación del cuestionario es fácil y rápida en el tiempo, por lo que su uso puede ser altamente sostenible y transferible a otros contextos. En este sentido, sería de gran utilidad administrar el cuestionario a estos mismos estudiantes en los próximos cursos con el fin de conocer si las acciones diseñadas e implementadas para dar respuesta a estas necesidades resultan eficaces. De ser así, estas necesidades del alumnado debieran quedar satisfechas y aparecer 
otras conforme avanzan en sus estudios. Asimismo, sería necesario administrar el cuestionario al alumnado que ingresa cada curso escolar en nuestra Facultad. Cada generación de estudiantes puede presentar necesidades diferentes. Debemos conocerlas para poder ser capaces de responder a ellas, lo que puede implicar una necesaria actualización continua del POU. El cuestionario elaborado puede ser igualmente transferible a otros Grados de la Universidad, resultando de utilidad para concretar el POU de los centros correspondientes. También puede resultar de interés para otras universidades.

En suma, los resultados de este trabajo permiten diseñar el POU de la Facultad de Educación de la Universidad de Zaragoza. Más concretamente los resultados permiten el posterior diseño y elaboración de actividades, recursos y materiales específicos que permitan trabajar con el alumnado para dar respuesta a las necesidades aquí expuestas, haciéndolo además de manera ajustada en el tiempo, es decir, cuando estas necesidades estén presentes en el alumnado y por tanto, nuestra ayuda y orientación pueda resultar de utilidad.

A pesar de los beneficios que implica este estudio, no puede pasarse por alto ciertas limitaciones del mismo.

En primer lugar, la administración del cuestionario ha tenido lugar en un solo momento temporal (al finalizar el primer semestre), preguntándose entonces al alumnado no solo por su grado de necesidad de información en ese momento sino también por el que tuvieron al inicio del curso. Esta información puede estar afectada por la calidad del recuerdo de cada estudiante. Es por ello que en futuras experiencias las necesidades del alumnado deben recogerse en relación con cada momento presente.

En segundo lugar, dado que el objetivo era conocer las necesidades del alumnado para a partir de ello diseñar acciones de orientación que respondieran a las mismas dentro del POU de la Facultad de Educación, y este contempla al alumnado de cada centro, no de cada titulación impartida en el mismo, las respuestas de los estudiantes han sido analizadas grupalmente, sin atender a posibles diferencias entre el alumnado de cada Grado. Por el mismo motivo tampoco se han analizado las posibles diferencias en las necesidades manifestadas por el alumnado en función de otras variables sociodemográficas como edad, sexo, modalidad de acceso a la universidad o lugar de residencia habitual durante el curso. Todo ello debiera ser considerado en el futuro, pues existen estudios en los que algunas de estas variables (como el sexo) han resultado explicativas de la adaptación al contexto universitario (Vergara, Boj, Barriga y Díaz, 2017). Todo ello permitiría diseñar dentro del POU de la Facultad acciones específicas para cada tipología de estudiante, lo que sin duda contribuiría a su mejor adaptación e integración.

En tercer lugar, es necesario complementar estos resultados referidos al análisis de necesidades del alumnado con aquellos resultantes del análisis de las propuestas de mejora del POU sugeridas por los mismos (dimensión tercera del cuestionario). Las sugerencias de mejora aportadas libremente por el alumnado constituyen un elemento clave a atender en nuestra función como tutores.

Todas estas acciones, que no agotan ni mucho menos todas las posibles, implicarían una mayor y mejor adaptación del alumnado a la universidad y por tanto, a su aprendizaje y formación. Sin embargo, atender de manera eficaz a todas las necesidades del alumnado requiere asimismo un soporte financiero y un capital humano que va más allá de la buena formación, compromiso y voluntad del profesorado/tutor. En este sentido no dudamos que las distintas instituciones implicadas en materia 
de educación lograrán ir desarrollando nuevas vías de ayuda para alcanzar la meta de una integración plena del alumnado que, a su vez, repercutirá en una mejora de su formación.

\section{Referencias bibliográficas}

Allueva, P. (2013). Mentoría en el Espacio Europeo de Educación Superior. II Congreso internacional sobre aprendizaje, innovación y competitividad. CINAIC 2013, pp. 773-778. Madrid, 6, 7 y 8 de noviembre. Fundación General de la Universidad Politécnica de Madrid. Allueva, P., Zulaica, F. y Abadía, A. R. (2016). Plan de Orientación Universitaria de la Universidad de Zaragoza. Integración de los estudiantes en la Universidad: Binomio Tutor-Mentor. En J. L. Castejón (Coord.), Psicología y Educación: Presente y Futuro (pp. 2273-2281). Madrid: Asociación Científica de Psicología y Educación.

Altschuld, J. W. y Watkins, R. (2014). Needs assessment: Trends and a View Toward the Future. New Directions for Evaluation, 144, 89-103.

Álvarez, M., Figuera, P. y Torrado, M. (2011). La problemática de la transición Bachillerato-Universidad en la Universidad de Barcelona. Revista Española de Orientación y Psicopedagogía, 22(1), 15-27.

Álvarez-Pérez, P. R. (2012). Los planes institucionales de tutoría y el desarrollo de competencias en el marco del Espacio Europeo de Educación Superior. Un estudio desde la perspectiva del alumnado. Perfiles Educativos, 34(137), 28-45.

Álvarez-Pérez, P. R. y López-Aguilar, D. (2017). Recursos de orientación para la transición académica y la toma de decisiones del alumnado: el programa "Universitarios por un día". Revista d'Innovació Docent Universitària, 9, 26-38.

Bernardo, A., Cerezo, R., Rodríguez-Muñiz, L. J., Núñez, J. C., Tuero, E. y Esteban, M. (2015). Predicción del abandono universitario: variables explicativas y medidas de prevención. Revista Fuentes, 16, 63-84.

Bernardo, A., Cervero, A., Esteban, M., Tuero, E., Solano, P. y Casanova, J. R. (2017). Proyecto E-Orientación, una necesidad desde el campo de la orientación educativa. Revista d'Innovació Docent Universitària, 9, 81-95.

Bisquerra, R. (Coord.) (2004). Metodología de la investigación educativa. Madrid: La Muralla.

BOE (2010). Estatuto del Estudiante Universitario. Real Decreto 1791/2010 de 30 de diciembre. Publicado el 31 de diciembre de 2010. Gobierno de España.

Chacón, S., Sanduvete, S., Portell, M. y Anguera, M. T. (2013). Reporting a program evaluation: Needs, program plan, intervention, and decisions. International Journal of Clinical and Health Psychology, 13, 58-66.

Cohen, L. y Manion, L. (2002). Métodos de Investigación educativa (2 ${ }^{\mathrm{a}}$ ed.). Madrid: La Muralla.

Colás, P. (2015). El abandono universitario. Revista Fuentes, 16, 9-14.

Esteban, M., Bernardo, A. B. y Rodríguez-Muñiz, L. J. (2016). Permanencia en la universidad: la importancia de un buen comienzo. Aula Abierta, 44, 1-6.

Figuera, P. y Álvarez, M. (2014). La intervención orientadora y tutorial en la adaptación y persistencia del alumnado en la universidad. Revista de Orientación Educacional, 28(54), 31-49.

Figuera, P. y Coiduras, J. L. (2013). La transición a la universidad: un análisis desde la diversidad de las voces de los estudiantes. Revista de Educación, 362, 713-736. 
García, B. (2010). La tutoría en la universidad de Santiago de Compostela: Percepción y valoración de alumnado y profesorado. Universidad de Santiago de Compostela. Tesis Doctoral. Recuperado de http://hdl.handle.net/10347/2840

García, M., Carpintero, E., Biencinto, C. y Núñez, M. C. (2014). La evaluación del proyecto SOU-estuTUtor: percepción de los mentores. Revista Complutense de Educación, 25(2), 433-455.

García, N., Asensio, I., Carballo, R., García, M. y Guardia, S. (2005). La tutoría universitaria ante el proceso de armonización europea. Revista de Educación, 337, 189-210.

Guerra-Martín, M. D., Lima, J. S. y Lima, M. (2016). Opiniones de los estudiantes de enfermería sobre las tutorías universitarias. Revista Española de Orientación y Psicopedagogía, 27(3), 104-121.

High Level Group on the Modernisation of Higher Education (2013). Report to the European Commission on Improving the quality of teaching and learning in Europe's higher education institutions. Luxembourg: Publications Office of the European Union.

Martínez, P., Martínez, M. y Pérez, J. (2016). ¿Cómo avanzar en la tutoría universitaria? Estrategias de acción: los estudiantes tienen la palabra. Revista Española de Orientación y Psicopedagogía, 27(2), 80-98.

Pérez, J. y Martínez, M. (2015). Tutoría universitaria y servicios de orientación: Dos realidades en un mismo contexto. Revista Electrónica Interuniversitaria de Formación del Profesorado, 18(2), 177-192.

Rodríguez-Hoyos, C., Calvo, A. y Haya, I. (2015). La tutoría académica en la educación superior. Una investigación a partir de entrevistas y grupos de discusión en la Universidad de Cantabria (España). Revista Complutense de Educación, 26(2), 467-481.

Stroebe, M., Schut, H. y Nauta, M. (2015). Homesickness: A systematic review of the scientific literature. Review Of General Psychology, 19(2), 157-171.

van-derHofstadt, C., Quiles, Y., Quiles, M. J. y Rodríguez, J. (2005). Necesidades de información al inicio de los estudios universitarios. Educación XXI, 8, 185-199.

Vergara, J. R., Boj, E., Barriga, O. y Díaz, C. (2017). Factores explicativos de la deserción de estudiantes de pedagogía. Revista Complutense de Educación,28(2), 609-630.

Villena, M. D., Muñoz, A. y Polo, M. T. (2013). La Unidad de Orientación de Centro como instrumento para la Orientación Universitaria. Revista de Docencia Universitaria, 11(2), 43-62. 
ANEXO 1: Cuestionario elaborado ad hoc

\section{CUESTIONARIO SOBRE NECESIDADES DE LOS ESTUDIANTES EN EL POU (FACULTAD DE EDUCACIÓN). Curso 2015-16}

Este cuestionario pretende conocer las necesidades de los estudiantes universitarios de nuevo ingreso en la Facultad de Educación.

Para ello, por favor, te rogamos indiques los datos que se solicitan en esta hoja, así como que cumplimentes el cuestionario que aparece detrás.

No hay respuestas correctas o incorrectas, sino que lo que es muy importante es contar con tus opiniones y necesidades anónimas. Gracias por tu colaboración.

\section{DATOS DE IDENTIFICACIÓN}

1. Grado:

$\square$ Magisterio en Educación Infantil

$\square$ Magisterio en Educación

Primaria

2. Edad (años):

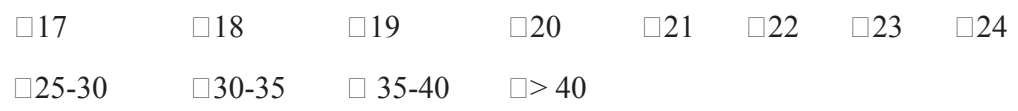

3. Sexo:

Hombre

Mujer

4. Acceso a la Universidad:

Bachillerato

Ciclo Formativo de Grado

Superior

Mayores de 25/40 años

Otros: especificar

5. Lugar de residencia habitual durante el curso:

Con mi familia habitual

En el colegio mayor/residencia

En piso compartido

Otros: especificar 


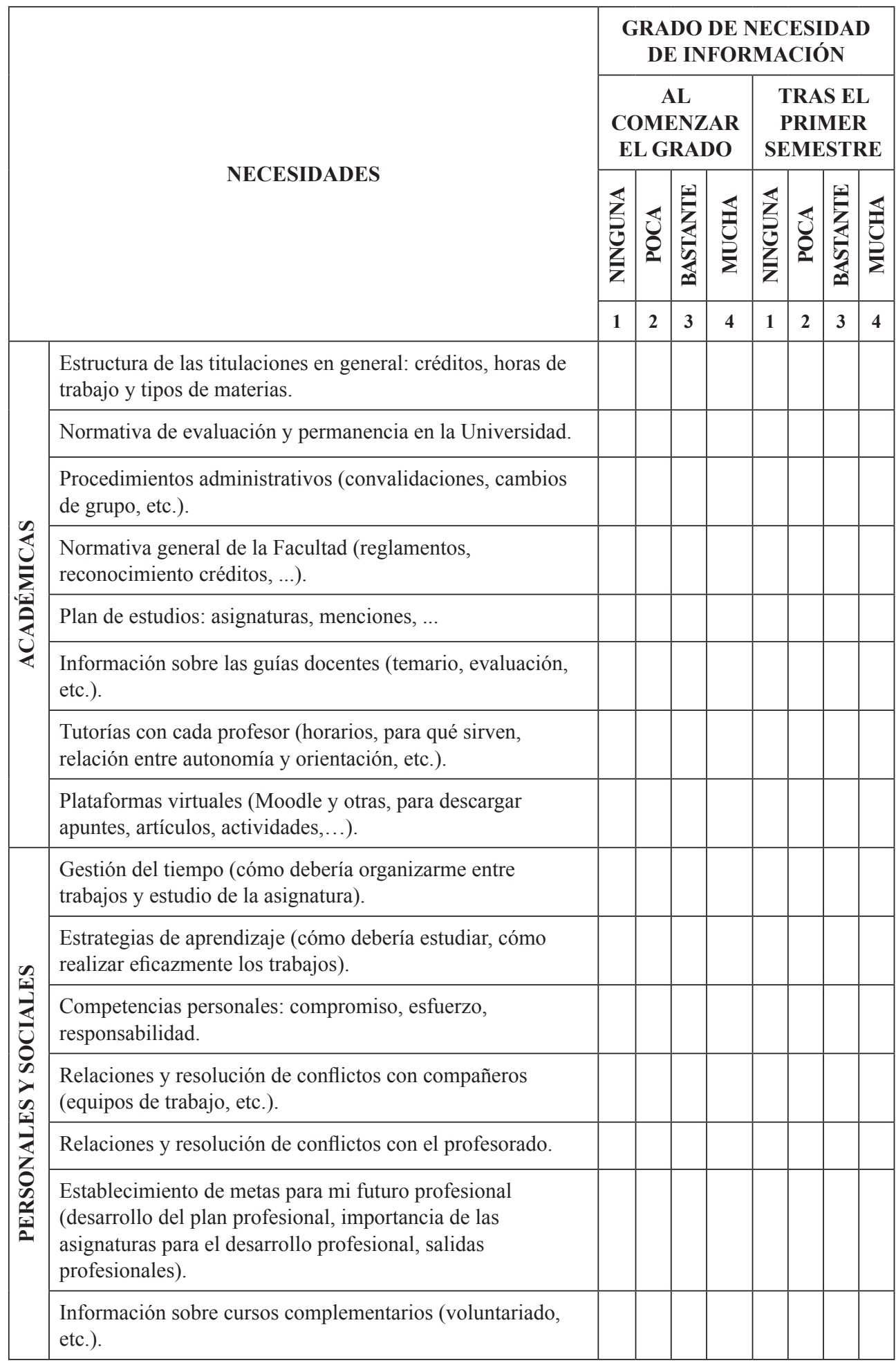




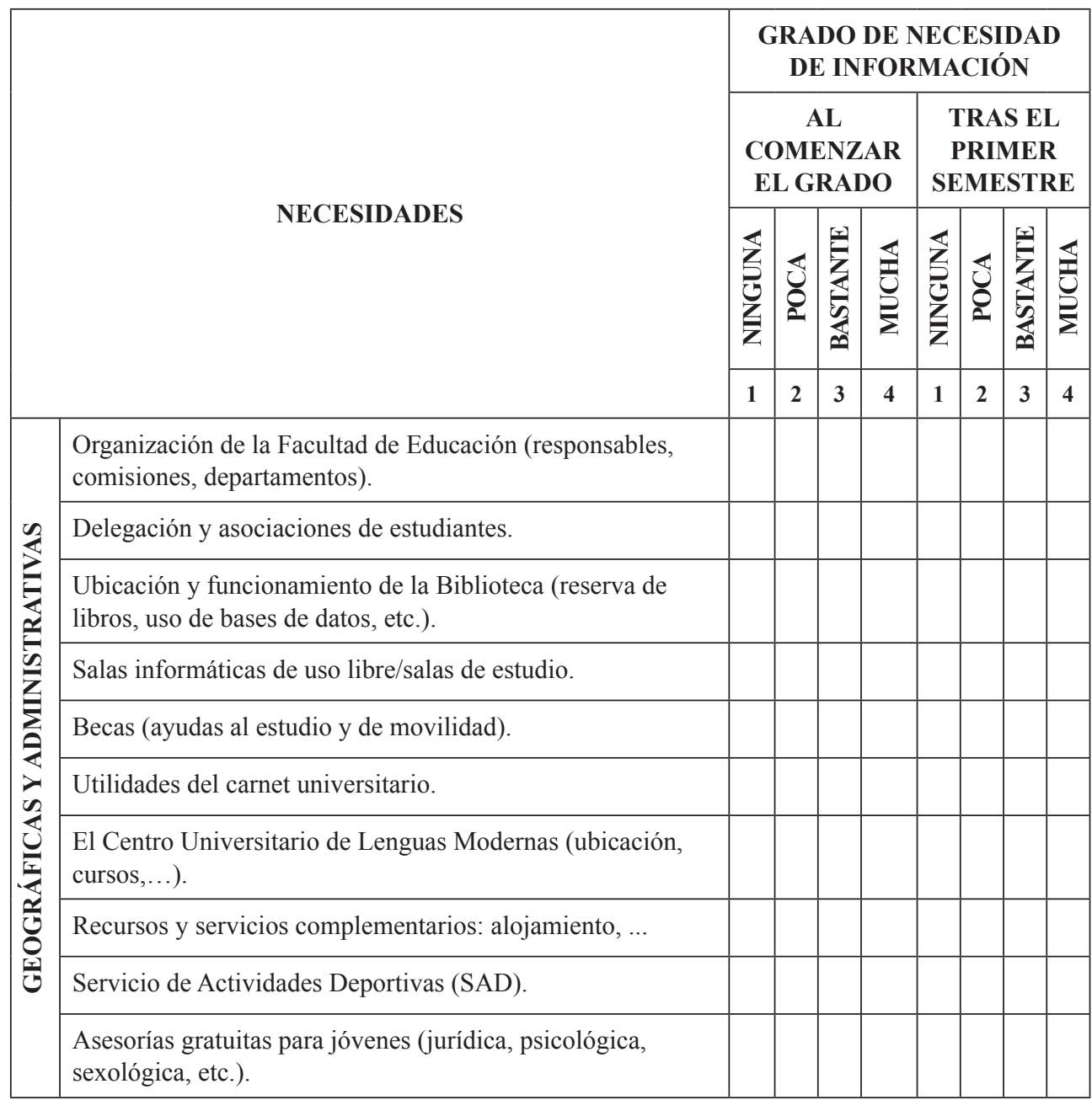

AÑADE LOS COMENTARIOS O SUGERENCIAS QUE CONSIDERES OPORTUNOS SOBRE EL PLAN DE ORIENTACIÓN UNIVERSITARIA (POU) DE LA FACULTAD DE EDUCACIÓN: 